\title{
Rheumatic heart disease
}

\section{Christina Maria Steger}

Department of Pathology, Academic Teaching Hospital Feldkirch, Affiliation of the Medical University Innsbruck, Feldkirch, Austria

\section{Correspondence to} Dr Christina Maria Steger, Christina.Steger@lkhf.at

Accepted 24 August 2015
CrossMark

To cite: Steger CM. BMJ Case Rep Published online: [please include Day Month Year] doi:10.1136/bcr-2015211943

\section{DESCRIPTION}

A 65-year-old man with a medical history of rheumatic fever in childhood reported thoracic pain while at work and collapsed. He died in the ambulance on the way to hospital due to ventricular fibrillation.

After the few episodes of rheumatic fever with subsequent pancarditis in childhood, the patient suffered from recurrent arrhythmias throughout his life and received medical treatment including $\beta$ blockers and diuretics in the past few years due to slowly progressive heart failure.

At autopsy, the heart showed signs of rheumatic heart disease with left ventricular dilation, eccentric left ventricular hypertrophy, posteromedial papillary muscle hypertrophy, and thickening and fusion of the chordae tendineae of the mitral valve (figures 1 and 2; in comparison, a heart with regular chordae tendineae in figure 3 ). Chordae tendineae of the anterolateral papillary muscle measured up to $1.2 \mathrm{~cm}$ in length and $1.1 \mathrm{~cm}$ in diameter (figure 4); chordae tendineae of the posteromedial papillary muscle measured up to $2 \mathrm{~cm}$ in length and $6 \mathrm{~mm}$ in diameter (figure 5).

Histopathological analysis of the heart revealed extensive tendon fibrosis and sclerosis of the chordae tendineae without inflammation, small fibrous scars in the left and right ventricle and pericardial fibrosis, as evidence of prior myocarditis and pericarditis. At the time of death, no inflammatory infiltrates in atria, ventricles and heart valves were found.

Rheumatic heart disease is a complication of acute rheumatic fever, an inflammatory disease that

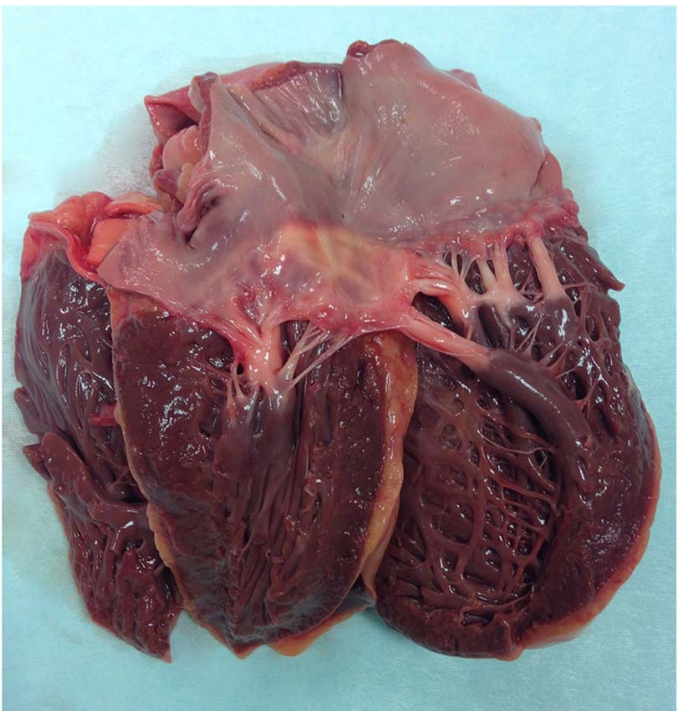

Figure 1 Heart with left ventricular dilation, thickening and fusion of the chordae tendineae of the mitral valve, and hypertrophy of the posteromedial papillary muscle.

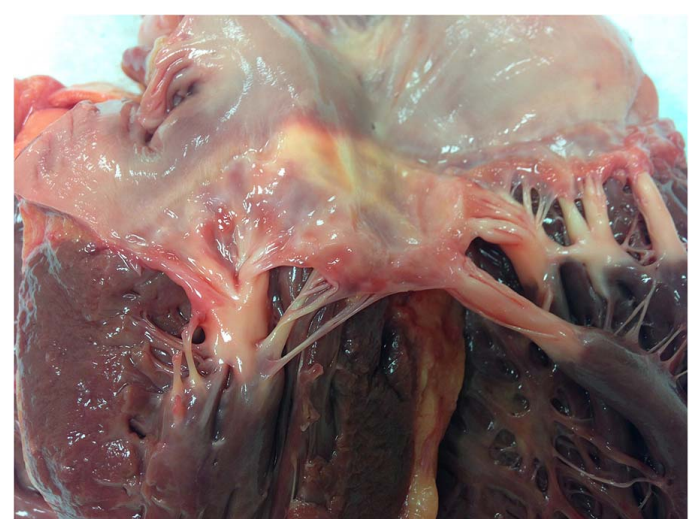

Figure 2 Close-up of a few of the chordae tendineae.

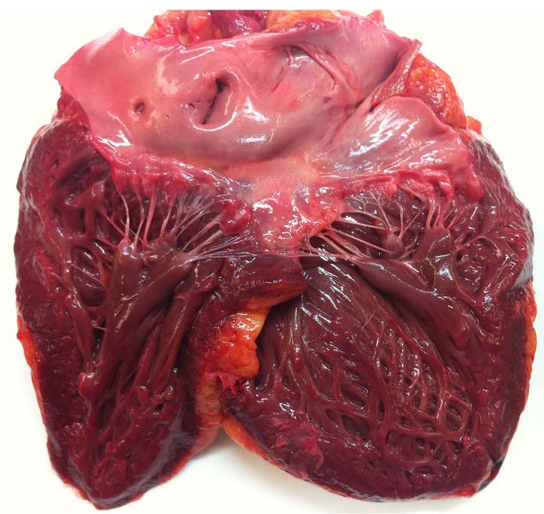

Figure 3 Regular heart with unremarkable chordae tendineae.

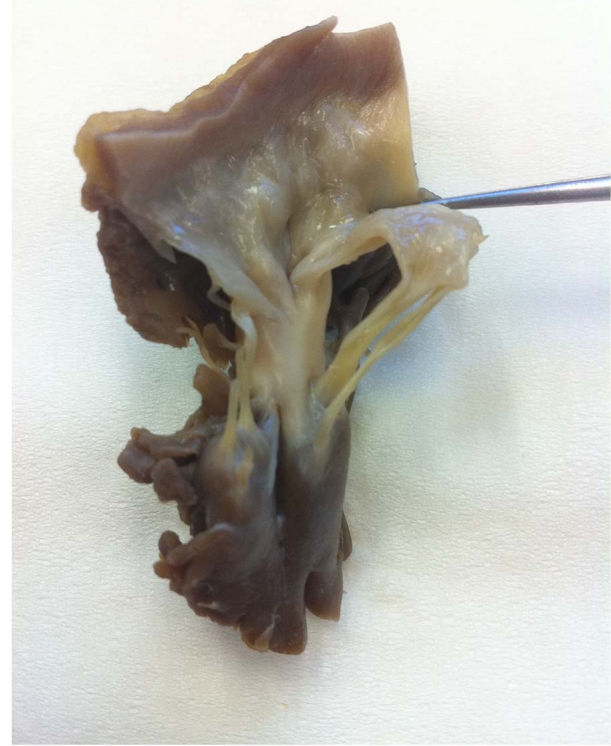

Figure 4 Chordae tendineae of the anterolateral papillary muscle. 


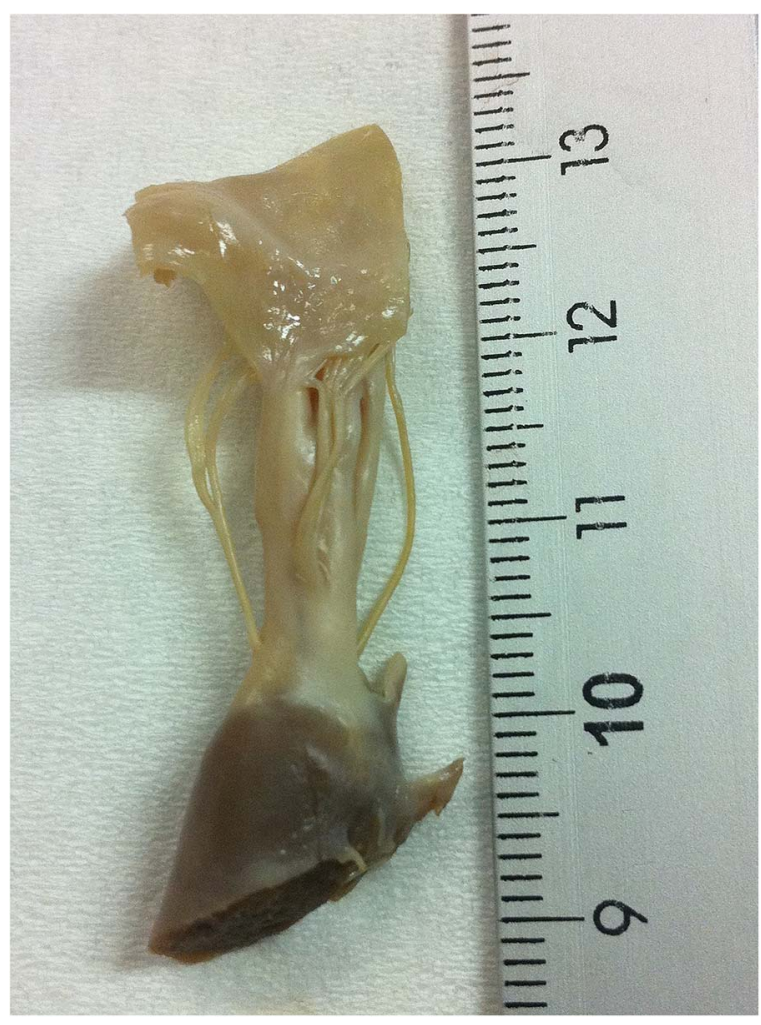

Figure 5 Chordae tendineae of the posteromedial papillary muscle.

can involve the heart, joints, skin and brain. Rheumatic fever typically develops 2-4 weeks after a throat infection caused by group A $\beta$-haemolytic Streptococcus. The diagnosis of acute rheumatic fever is established by the Jones criteria. ${ }^{1}$ Heart involvement generally develops over time and may include mitral and aortic valve stenosis or insufficiency, pancarditis, arrhythmias and heart failure.

The mitral valve is most commonly and severely affected (65-70\% of patients), followed by the aortic valve $(25 \%)$ and the tricuspid valve (10\%). Fusion of the valve apparatus develops 2-10 years after an episode of acute rheumatic fever, and recurrent episodes may cause progressive damage to the valves. Fusion occurs at the level of the valve commissures, cusps, chordal attachments, or any combination of these. Fibrosis and scarring of valve leaflets, commissures, cusps and chordae tendineae lead to abnormalities that can result in valve stenosis or regurgitation or a combination of stenosis and insufficiency. ${ }^{2}$ Variables that correlate with severity of valve disease include the number of previous attacks of rheumatic fever, and the length of time between the onset of disease and the start of therapy.

Treatment of rheumatic heart disease consists of medical treatment of heart failure, heart valve replacement and heart valve repair by replacement of chordae tendineae.

\section{Learning points}

- Rheumatic heart disease is a complication of acute rheumatic fever caused by group A $\beta$-haemolytic Streptococcus and develops over time.

- Heart involvement can include mitral and aortic valve stenosis or insufficiency, pancarditis, arrhythmias and heart failure, and is characterised by fibrosis and scarring of the leaflets, commissures and cusps.

- Treatment of rheumatic heart disease consists of medical treatment of congestive heart failure and heart valve surgery.

Competing interests None declared.

Patient consent Obtained.

Provenance and peer review Not commissioned; externally peer reviewed.

\section{REFERENCES}

1 [No authors listed]. Guidelines for the diagnosis of rheumatic fever. Jones Criteria, 1992 update. Special Writing Group of the Committee on Rheumatic Fever, Endocarditis, and Kawasaki Disease of the Council on Cardiovascular Disease in the Young of the American Heart Association. JAMA 1992;268:2069-73.

2 Brice EAW, Commerford PW. Rheumatic fever and valvular heart disease. In: Rosendorff C, ed. Essential cardiology: principles and practice. Totowa, NJ: Humana Press, 2005:545-63.

Copyright 2015 BMJ Publishing Group. All rights reserved. For permission to reuse any of this content visit http://group.bmj.com/group/rights-licensing/permissions.

BMJ Case Report Fellows may re-use this article for personal use and teaching without any further permission.

Become a Fellow of BMJ Case Reports today and you can:

- Submit as many cases as you like

- Enjoy fast sympathetic peer review and rapid publication of accepted articles

- Access all the published articles

- Re-use any of the published material for personal use and teaching without further permission

For information on Institutional Fellowships contact consortiasales@bmjgroup.com

Visit casereports.bmj.com for more articles like this and to become a Fellow 